\title{
Health information on the internet: an issue of social inequality in public health
}

\begin{abstract}
T. Stutz Steiger, MD, MSC is head of the Public Health Unit at Swiss Federal Office of Public Health, and member of the committee of the Swiss Society for Public Health. M. Duetz Schmucki, MD, MPH, is a researcher and teacher at the Division of Social and Behavioural Health, Institute for Social and Preventive Medicine in Bern
\end{abstract}

e-health is a term that is usually used to refer to innovations in health services such as telemedicine and data networking, developments that have already featured in a large number of national and international reports.

However, the general population can also play an increasingly active role by using the internet as a source of information on health matters. Last year, $47.6 \%$ of people in Switzerland (comprising just over $60 \%$ of men and just under $40 \%$ of women) accessed the internet every day or several times a week, and the trend is a growing one (Bucher et al. 2003). The outcome of the „World Summit on the Information Society ", which took place in Geneva in December 2003, showed that people using the internet have also caught the attention of politicians. This international conference developed a basis for promoting information strategies on a global level. The overriding objectives in this instance are to combat poverty, empower disadvantaged groups, promote health and pursue prevention goals. The provision of electronic infrastructure and promotion of its use supporting various aspects of life, including health, are defined as matters requiring urgent attention.

A great number of providers are present on the internet, some of them representing conflicting interests. The internet community is being joined by a growing number of patient organizations and service providers keen to benefit from the advantages offered by this new medium. Commercial suppliers are also using the web increasingly to publicize and market their products. This development naturally provides new opportunities but it is not free of risks, and the public health sector would do well to turn its attention to this field. Which aspects require particular vigilance? The two areas of prime concern are the social inequality in access to and use of the internet and the need to assure the quality of the information provided.

One of the great advantages of the internet is the opportunity it offers to enhance knowledge and thus to promote the autonomy and health competence of the population. However, this can only be achieved if certain basic conditions, closely linked to the question of social inequality, are met. Age, educational status and income are important factors that determine the use of (or failure to use) the internet (Baker et al. 2003).

The Federal Council's strategy for an information society was announced in Switzerland in 1998. This strategy states that the medium offers a great opportunity for Switzerland, but that potential negative consequences must be avoided. An information society that involves all interest groups must be promoted by emphasizing the fundamental principles of access for all, empowerment of the population as a whole, and freedom in designing the information offered. This is a task that falls largely to the educational sector.

Scrutiny and quality assurance of health-related information, on the other hand, are tasks that are best handled by the health sector. While the internet can provide high quality health information, there also is a clear danger of misinformation.

When it comes to health issues, what are the risks and potential damage associated with misinformation? The literature shows that the quality of the information on the internet varies between "extremely useful" and "harmful to health". The relevance of the information, along with the differentiation of commercial and non-commercial interests, must always be critically examined. An outstanding example of the involved risks is the recent warning issued by Swissmedic, the Swiss Agency for Therapeutic Products, 
about medications offered on the internet which contain psychotropic substances capable of causing serious damage to health (Swissmedic 2003).

On an international level, and in the EU in particular, efforts are certainly being made to examine the quality of the vast quantities of health information on the internet. A small number of private initiatives in Switzerland are using quality seals, quality labels and internet portals in an attempt to ensure that high-quality information is provided. One example is the Health on the Net Foundation (www.hon.ch) based in Geneva, whose stated objective is ,to promote the effective and reliable use of the new technologies for telemedicine in health care around the world". The foundation offers a search tool, medhunt, and a quality label. However, very few users are familiar with the available tools.
A high-quality, validated quality assurance system with which people are familiar can improve the usefulness of the internet as a source of information. At the very least, a system of this type should show whether the health information offered by a provider is sound, thus enabling users to assess the quality of that information.

Despite the current emphasis on cutting costs, it is more than desirable to focus some attention in the complex field of e-health on the acquisition of information at population level. Promoting individual responsibility and empowerment by providing reliable information could, with a little assistance, counter the risks posed by self-serving commercial providers.

\section{Therese Stutz Steiger, Margreet Duetz Schmucki}

\section{References}

Bucher S, Niemann S, Abel T (2003). Thema Gesundheit: welche Informationsquellen nutzen SchweizerInnen? Univox Teil I C Trendbericht Gesundheit 2002. Bern: Universität Bern, Abteilung für Gesundheitsforschung des ISPM.
Baker L, Todd HW, Singer S, Bundorf MK (2003). Use of the internet and e-mail for health care information. JAMA 289: 2400-6.
Swissmedic, Schweizerisches Heilmittelinstitut, Kommunikation (2003). Gesundheitsrisiko: Swissmedic warnt vor dem Bezug von Medikamenten via Internet. Medienmitteilung. www.swissmedic.ch.

(20) To access this journal online:

(20) http://www.birkhauser.ch 